\title{
Designing of Mathematical E-courses in the Digital Learning System NOMOTEX
}

\author{
Yuriy I. Dimitrienko ${ }^{1}$, Elena A. Gubareva ${ }^{1}$, Anna E. Pichugina ${ }^{1 *}$, Dmitriy A. Chebakov ${ }^{1}$, and \\ Ivan A. Tumanov ${ }^{1}$ \\ ${ }^{1}$ Bauman Moscow State Technical University, 2nd Baumanskaya str., 5/1, 105005, Moscow, Russia
}

\begin{abstract}
The paper describes a methodology for the design of digital mathematical courses for engineers in the digital learnig system Nomotex (DLS "NOMOTEX") [1], developed at the Department of Computational Mathematics and Mathematical Physics, Bauman Moscow State Technical University, based on the usage of the Knowledge Base created in the DLS "NOMOTEX". The technique allows one to create mathematical courses of varying complexity and resulting level of knowledge, depending on the direction of training (specialty).
\end{abstract}

\section{Introduction}

For different areas of training and specialties, different mathematical courses with variable depth of content are required, which correspond to the competencies of university graduates. $[2,3,4,5,6]$ The need for designing personalized courses occurs during training on individual trajectories. $[7,8,9,10,11,12]$

\section{Designing of Mathematical E-courses}

In the DLS "NOMOTEX" (Fig. 1), developed at the Department of Computational Mathematics and Mathematical Physics, Bauman Moscow State Technical University, a specialized subsystem "Designing Educational Programs" was created, which allows one to design mathematical courses from the existing Mathematical Knowledge Base, while maintaining the logic and sequence of all elements of the Knowledge Base, as well as practical interactive lessons, automated tasks for independent work and tests.

* Corresponding author: opichugina@bmstu.ru 


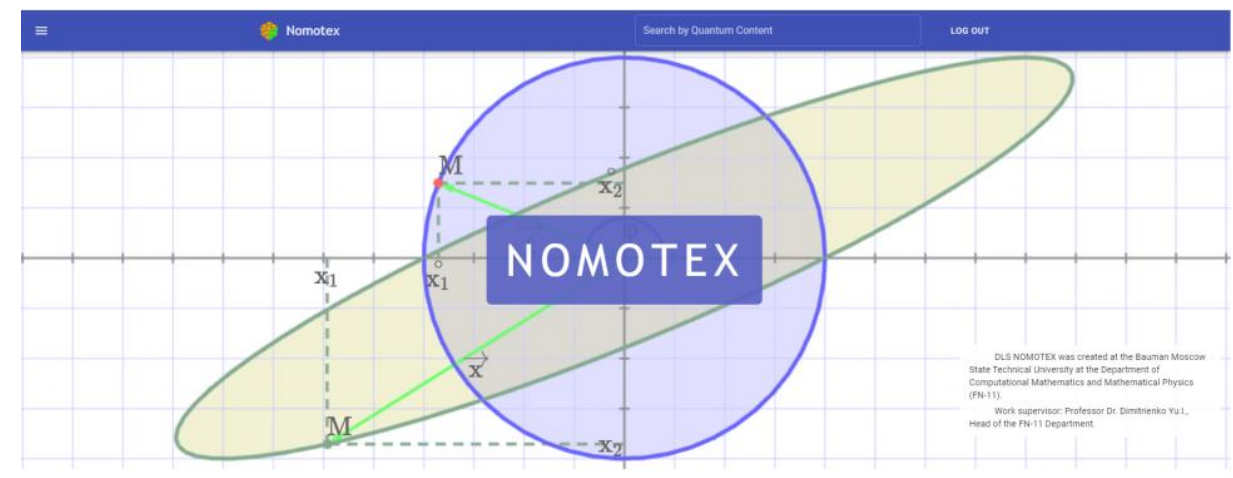

Fig. 1. The main window of the DLS "NOMOTEX".

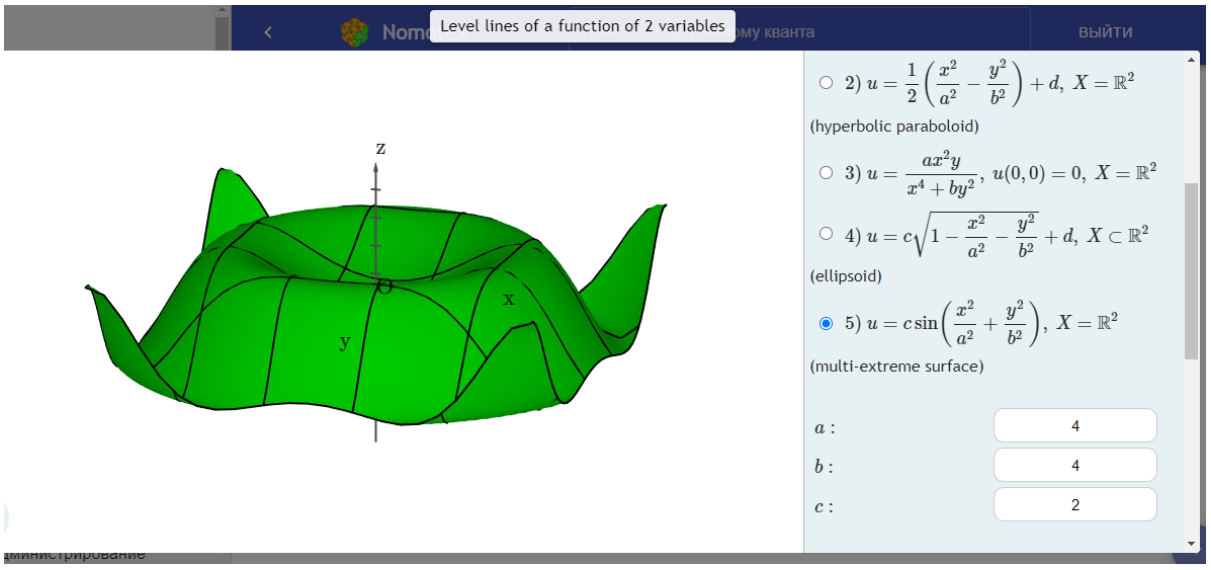

Fig. 2. An example of a "Mathematical Example" in a Quantum of Knowledge.

The neural network base of mathematical knowledge has a hierarchical structure [1]: Disciplines, chapters, paragraphs, quanta of knowledge, which may include mathematical examples (Fig. 2). The new course being created will have a similar hierarchical structure: chapters, paragraphs, quanta of knowledge. All courses are based on the same structure called the "Knowledge Base" (Fig. 3).

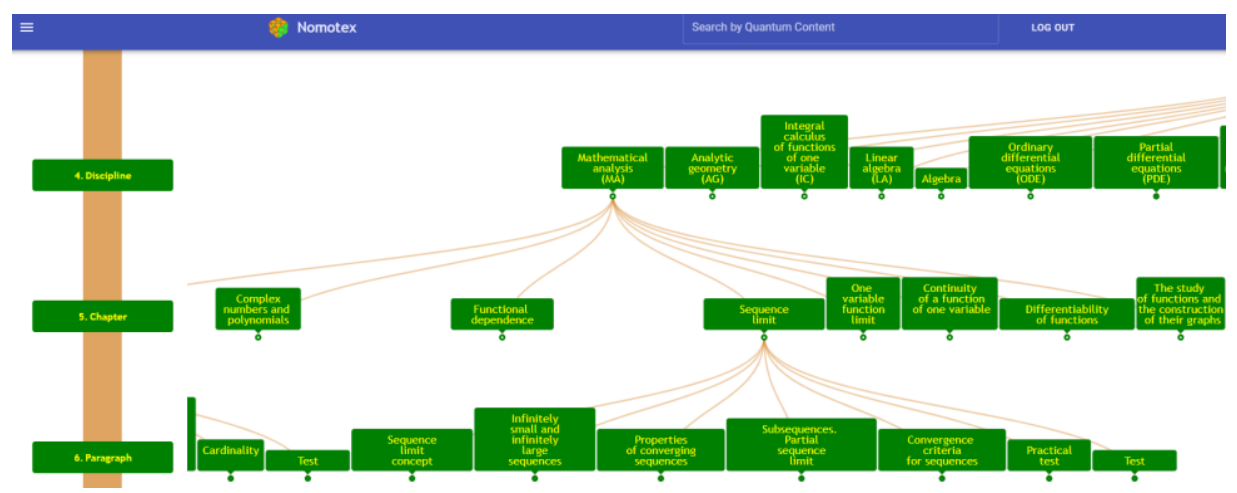

Fig. 3. The "Knowledge Base" DLS "NOMOTEX". 
The first level of the structure is the direction of science (Physics and Mathematics, Chemical Sciences, Biological Sciences, etc.), the second is Sciences (for physics and mathematics these are: Mathematics, Mechanics, Astronomy, Physics), the third is the section of science (for mathematics it is fundamental and applied mathematics), the fourth disciplines (for fundamental mathematics it is: "Mathematical analysis", "Analytical geometry", "Integral calculus of functions of one variable", "Linear algebra", etc.). Starting with the choice of the discipline, the fourth, fifth and sixth levels are devoted to the discipline itself. The fourth level of discipline is the chapters included in the subject.

At the same time, while the Knowledge Base contains all the materials of the DLS "NOMOTEX", the course contains only those that are necessary for studying for a specific specialty. In addition, the course may contain more than one subject from the Knowledge Base, and the division into lectures in accordance with the curriculum, and the rating of each student taking the course.

To create a new mathematical course, the subsystem "Designing neural network EP" is used, which allows you to create a mathematical course of any complexity included in the main educational program of the chosen field of study (specialty).

When entering the element "Designing neural network EP", the main input fields are displayed (Fig. 4):

- Code and name of the direction of training (specialty);

- Profile code (specialization);

- Profile name (specialization);

- Course name;

- List of paragraphs.

The code and name of the direction of training (specialty) must be entered in accordance with the Lists of areas of training for higher education - bachelor's degree, specialty, then the code and the name of the profile (specialization), the name of the course being constructed are entered.

After the introduction of these data, a design solution for creating a course follows (Fig. 4). In the existing titles of paragraphs of all disciplines from the knowledge base, those paragraphs that conceptually correspond to the created course are selected in an orderly manner. Orderly selection is important for course creation because the sequence of paragraphs in the tree of the course being created depends on the order of selection. Further in the selected paragraphs are selected "quanta of knowledge" that are included in the created course. The quantum of knowledge can be included in the course "with proof" or "without proof". 


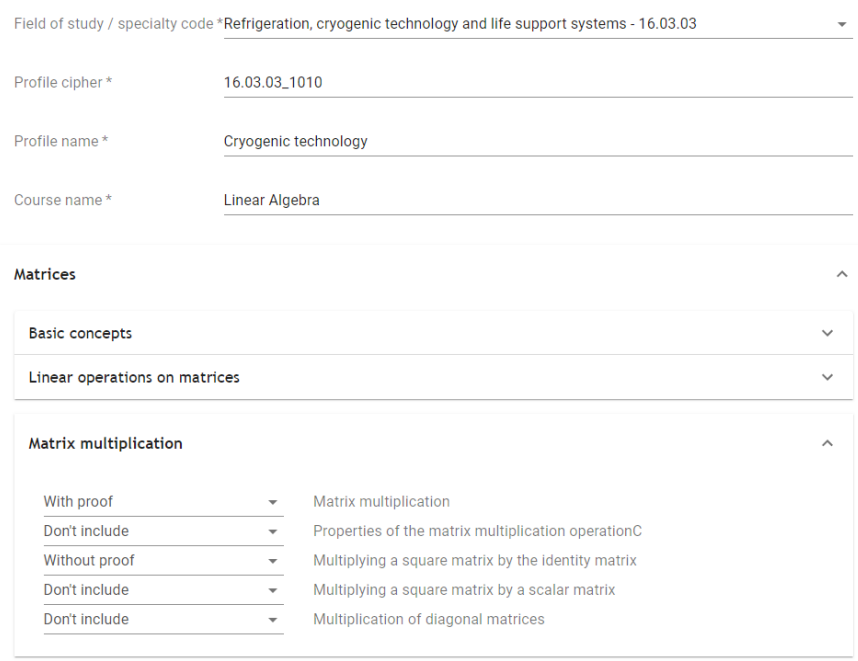

Fig. 4. Window of the subsystem "Designing neural network EP" DLS NOMOTEX.

After the orderly selection of all paragraphs and all quanta in the paragraphs, the button "create a course" is pressed. The created course will include all elements of the classic course: theory and practice.

An important feature of the ability to design courses is that courses can be composite, i.e. contain within itself several disciplines from the Knowledge Base. For example, the course "Multiple Integrals, Series, Complex Analysis", traditionally taught in the 3rd semester of training in the specialty "Aircraft Control Systems" of the Bauman Moscow State Technical University (BMSTU). This course consists of sections of several mathematical disciplines from the Knowledge Base: Multiple Integrals, Field Theory, Series, and Complex Analysis.

In the Fig. 5: an example of a course containing several disciplines: the transition from the discipline "Multiple integrals" to the discipline "Field theory" occurs as a transition between adjacent paragraphs within the same course.

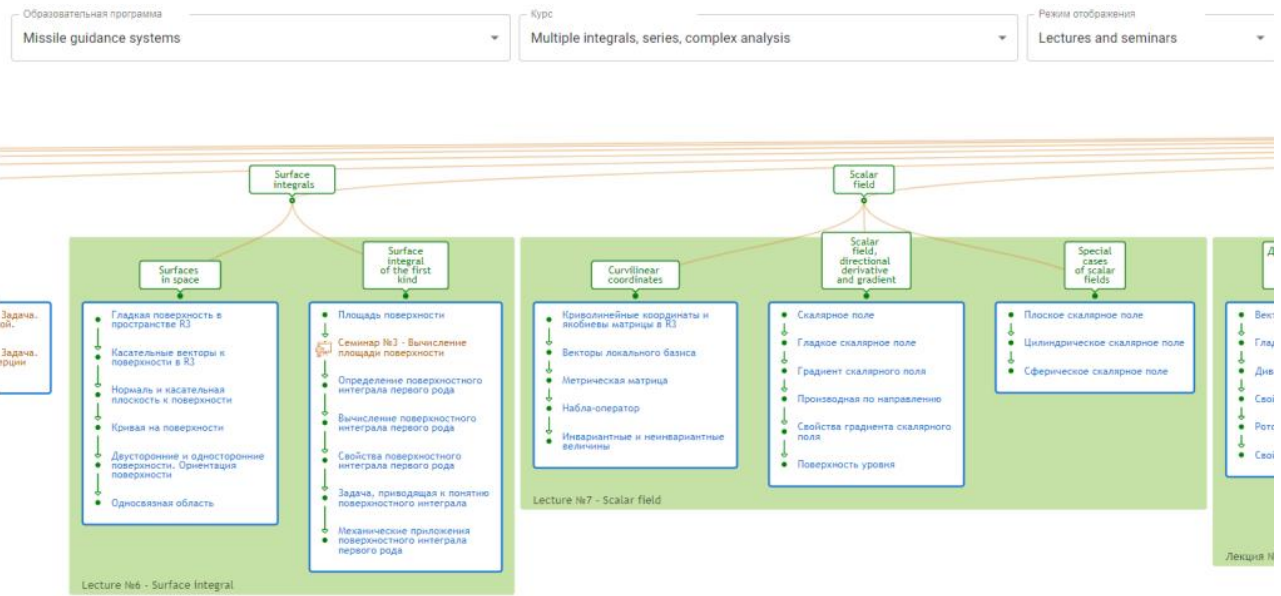

Fig. 5. The course "Multiple Integrals, Series, Complex Analysis". 
Lectures in accordance with the schedule are highlighted in green, seminars are highlighted in red. The course necessarily includes quanta, which are the theoretical basis for solving practical problems at seminars, and practical problems are inextricably linked with the theoretical course.

The transition between the disciplines "Series" and "Complex analysis" looks similar in the same course (Fig. 6):
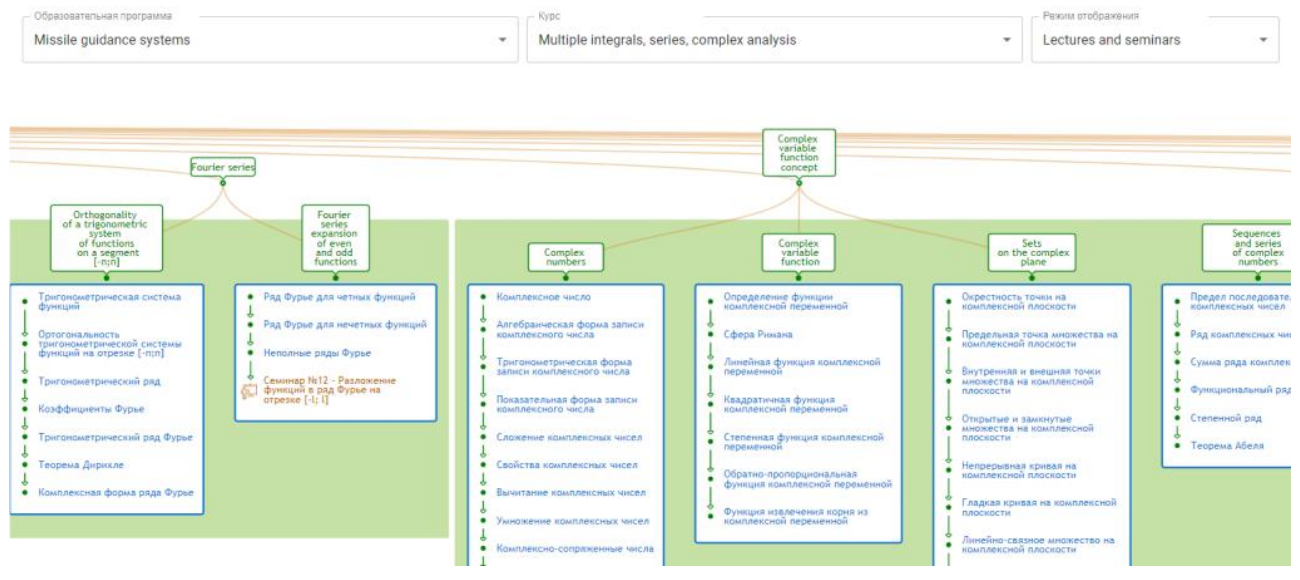

Fig. 6. The course "Multiple Integrals, Series, Complex Analysis".

Thus, the course developed using this module will contain only selected quanta that are necessary for students to study this specific specialty. In this case, the quanta can be either included without proof, or interchanged, if necessary, interchanged the paragraphs containing these quanta, and split one paragraph into several.

Also for the semester, rating tables are implemented for groups enrolled in the course (Fig. 7):

\begin{tabular}{|c|c|c|c|c|c|c|c|c|c|c|c|c|c|c|c|}
\hline \multicolumn{16}{|c|}{$\begin{array}{l}\text { Rating } \\
\text { AK1-31-Integral calculus and differential equations }\end{array}$} \\
\hline \multicolumn{16}{|c|}{ Teachers: Timofeev Valery Nikolaevich } \\
\hline \multirow{4}{*}{ No. } & \multirow{2}{*}{$\begin{array}{l}\text { student } \\
\text { sumame }\end{array}$} & \multicolumn{6}{|c|}{ Integral calculus } & \multicolumn{6}{|c|}{ Differential Equations } & \multirow[b]{2}{*}{ Exam } & \multirow{2}{*}{$\begin{array}{l}\text { Ranking for worki in the } \\
\text { semester Rc }\end{array}$} \\
\hline & & MK IFoP & $\begin{array}{l}\text { KR:1 } \\
\text { IFoP }\end{array}$ & $\begin{array}{l}\text { O2 No. } 1 \\
\text { IFOP }\end{array}$ & $\begin{array}{l}\text { RK No. } 1 \\
\text { IFOP }\end{array}$ & Abstract & Total & MK. Du & $\begin{array}{l}\text { KR No. } 1 \\
\text { ODE }\end{array}$ & $\begin{array}{l}\text { DZ No. } 1 \\
\text { ODU }\end{array}$ & $\begin{array}{l}\text { Re No. } 1 \\
\text { OOU }\end{array}$ & Abstract & Total & & \\
\hline & Max score & 6 & $10+1 *$ & 4 & $9+1$. & 4 & 35 & 6 & $10+1$. & 5 & , & 4 & 35 & 30 & 100 \\
\hline & Min credit & 3 & 7 & 3 & 6 & 2 & 21 & 3 & , & 3 & 6 & 2 & 21 & 18 & 60 \\
\hline 1 & 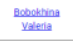 & $\begin{array}{c}1+0.5+0.5+1+1+0.5= \\
4.5\end{array}$ & 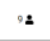 & 4 & 2 & 42 & 30.5 & $\begin{array}{c}0.5+1+0.5+0.5+1+1= \\
4.5\end{array}$ & 112 & 3 & $\circ$ & 42 & 24.5 & 22 & $\pi$ \\
\hline 2 & 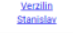 & $1+1+1 * 0.5 * 1+0.5=5$ & 82 & 4 & 72 & 42 & 28 & $0.5+1+1+1+1+1=5.5$ & 112 & 52 & $\circ$ & 42 & 25.5 & 30 & 83.5 \\
\hline 3 & Subanow toest & $\begin{array}{c}0.5+0.5+0.5+0.5+1+ \\
0.5=3.5\end{array}$ & 7 & 3 & 9 & $2 \mathbf{2}$ & 23.5 & $\begin{array}{c}0.5+0.5+0.5+0.5+1+1 \\
=4\end{array}$ & 8 & 3 & 82 & 2 & 25 & 182 & 66.5 \\
\hline 4 & 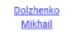 & $\begin{array}{c}0.5+1+0+0.5+0.5+0.5 \\
=3\end{array}$ & 92 & 4 & ${ }^{82}$ & 2 & 26 & $0.5+1+1+1+0.5+1=5$ & 9 & 5 & $\circ$ & 32 & 22 & 26 & 74 \\
\hline 5 & $\begin{array}{l}\text { Epogova } \\
\text { valeentina }\end{array}$ & $1+1+0.5+1+0.5+1=5$ & 72 & 4 & 82 & 42 & 28 & $\underset{=4}{0.5+1+0.5+1+0.5+0.5}$ & 112 & 5 & e & 42 & 24 & 24 & 76 \\
\hline
\end{tabular}

Fig. 7. Rating of a study group for the course "Integrals and Differential Equations".

The rating fully reflects the list of tests that are passed by the group during the semester. At the same time, the tests can be changed for each specific area of training, regardless of other areas: the assignment of tasks and their composition can be changed. Tickets related to every test are generated with the ability to create several templates for generation. This means, for example, that the control event contains 10 different tasks, and the student can receive 5 of them according to the assigned template, while the difficulty of the ticket for each student remains the same. 


\section{Conclusions}

With the help of the created subsystem "Designing neural network EP" DLS NOMOTEX electronic interactive courses were created: "Mathematical analysis", "Multiple integrals and series" and others for various engineering areas of training. Thus, the tool for constructing neural network EPs allows one to flexibly form educational courses for any student curriculum.

\section{References}

1. Y.I. Dimitrienko, E.A. Gubareva, Neural network model of mathematical knowledge and development of information and educational environment for mathematical training of engineers, Journal of Physics: Conference Series, 1141 (1) (2018)

2. A.A. Aleksandrov, V.A. Devisilov, M.V. Ivanov, A role of education system in creation of safety culture, Chemical Engineering Transactions, 53, pp. 211-216 (2016)

3. A.O. Karpov, Generative learning in research education for the knowledge society, Mathematics Education, 11 (6), pp. 1621-1633 (2016)

4. A.O. Karpov, University 3.0 as a corporate entity of knowledge economy: Models and missions, International Journal of Economics and Financial Issues, 6 (Special Issue), pp. 354-360 (2016)

5. O. Egorova, D. Shcherbinin, Creating technical heritage object replicas in a virtual environment, Frontiers of Mechanical Engineering, 11 (1), pp. 108-115. (2016)

6. V.S. Shcherbakov, A.L. Makarov, N.V. Buldakova, T.P. Butenko, L.V. Fedorova, A.R. Galoyan, N.I. Kryukova, Development of higher education students' creative abilities in learning and research activity, Eurasian Journal of Analytical Chemistry, 12 (5), pp. 765-778 (2017)

7. N.A. Zaitseva, A.A. Larionova, A.S. Fadeev, V.V. Filatov, V.N. Zhenzhebir, T.S. Pshava, Development of a strategic model for the formation of professional competencies of university students, Eurasian Journal of Analytical Chemistry, 12 (7), pp. 1541-1548 (2017)

8. N.A. Serdyukova, V.I. Serdyukov, A.V. Uskov, V.A. Slepov, C. Heinemann, Algebraic formalization of sustainability in smart university ranking system, Smart Innovation, Systems and Technologies, 75, pp. 459-474 (2017)

9. O. Bannova, V. Mayorova, Building trans-national and multi-disciplinary academic curricula through adaptation of a project-based approach, International Astronautical Congress, IAC, 3, pp. 1590-1598 (2017)

10. A.O. Karpov, Designing the university's creative environment: Structural-functional analysis, Intelligent Systems and Computing, 857, pp. 319-332 (2019)

11. S.A. Gudkova, T.S. Yakusheva, A.A. Sherstobitova, V.I. Burenina, Modeling of scientific intercultural communication of the teaching staff at smart university, Smart Innovation, Systems and Technologies, 144, pp. 551-560 (2019)

12. G. Gavrilenko, U. Danilova, E. Artamonova, L. Krivshenko, Setting tasks for performing creative assignments by students of first-second years of a technical university, ACM International Conference Proceeding Series, pp. 95-99 (2019) 